\title{
Lilliputian Hallucinations and Marijuana Dependence in a Bipolar Patient
}

\author{
Matthew L. Bush M.S. IV \\ Joan Edwards School of Medicine and Marshall University \\ Saurabh Gupta M.D. \\ MM Bateman Hospital; Department of Psychiatry, Joan Edwards School of Medicine and Marshall \\ University
}

\section{Follow this and additional works at: https://jdc.jefferson.edu/jeffjpsychiatry \\ Part of the Psychiatry Commons \\ Let us know how access to this document benefits you}

\section{Recommended Citation}

Bush, Matthew L. M.S. IV and Gupta, Saurabh M.D. (2002) "Lilliputian Hallucinations and Marijuana Dependence in a Bipolar Patient," Jefferson Journal of Psychiatry. Vol. 17 : Iss. 1 , Article 8.

DOI: https://doi.org/10.29046/JJP.017.1.007

Available at: https://jdc.jefferson.edu/jeffjpsychiatry/vol17/iss1/8

This Article is brought to you for free and open access by the Jefferson Digital Commons. The Jefferson Digital Commons is a service of Thomas Jefferson University's Center for Teaching and Learning (CTL). The Commons is a showcase for Jefferson books and journals, peer-reviewed scholarly publications, unique historical collections from the University archives, and teaching tools. The Jefferson Digital Commons allows researchers and interested readers anywhere in the world to learn about and keep up to date with Jefferson scholarship. This article has been accepted for inclusion in Jefferson Journal of Psychiatry by an authorized administrator of the Jefferson Digital Commons. For more information, please contact: JeffersonDigitalCommons@jefferson.edu. 


\title{
Lilliputian Hallucinations and Marijuana Dependence in a Bipolar Patient
}

\author{
Matthew L. Bush ${ }^{1}$ (MS IV) and Saurabh Gupta M.D. ${ }^{2}$
}

\begin{abstract}
Lilliputian hallucinations are rarely seen in manic patients. Here we present a case of isolated lilliputian hallucinations against a backdrop of psychosis and marijuana use. The phenomenon is interesting and worth following up with. The patient recovered and a brief literature search is included.

\section{INTRODUCTION}

In 400 A.D. Saint Macarius, the Egyptian, experienced and described a bizarre perceptual phenomenon (2). After a period of fasting, he visualized "little strangers" which he believed were "daemons like flies settling on his mouth (2)." In 1726, Jonathan Swift coined the term "lilliputian" in his satirical book, Gulliver's Travels. He described the inhabitants of the land of Lilliput by writing, "I felt something alive moving on my Leg, which advancing gently forward over my Breast, came almost up to my Chin; when bending mine Eyes downwards as much as I could, I perceived it to be a human Creature not six Inches high, with a Bow and Arrow in his Hands, and a Quiver at his back (3)." In 1909, Leroy utilized the term "lilliputian" in the description of a specific type of perceptual abnormality (4).

Visual hallucinations in which people, animals, or objects appear reduced in size are referred to as lilliputian hallucinations. Hallucinations of this type have been associated with various psychiatric conditions $(4,5,12,14,15,16)$, senile dementia (16), neurologic disorders $(8-10,17)$, toxic metabolic states $(6,7)$, head trauma (13), AIDS (13), and ophthalmologic disorders (11). This phenomenon can be pleasurable (4) or terrifying (2) depending on the content of the hallucination and the context in which it is experienced.
\end{abstract}

\section{CASE REPORT}

Mr. W is a 24 year-old Afro-American male who has been hospitalized for bipolar disorder, type I, manic type on five different occasions. He has a 10 -year

\footnotetext{
${ }^{1}$ Matthew L. Bush is a medical student at Joan Edwards School of Medicine and Marshall University.

${ }^{2}$ Saurabh Gupta, M.D., Psychiatrist, MM Bateman Hospital and Assistant Professor, Dept. of Psychiatry, Joan Edwards School of Medicine and Marshall University, Huntington.
} 
history of marijuana dependence. He uses marijuana 4-5 times a week. However, the frequency of marijuana use escalates during his manic episodes. He denies use of other illicit drugs. He has never displayed any signs of psychosis with his mania or drug use. The patient lacks a history of head trauma, neurologic impairment, and medical illness.

He was arrested for possession of marijuana. In the two weeks prior to his arrest, he was noncompliant with his medication and he exhibited signs of hypomanic behavior and increased marijuana use. While in prison he was exposed to marijuana, possibly mixed with a hallucinogen, and he began exhibiting bizarre behavior such as kissing and rubbing the prison cell walls inappropriately and smearing his feces around the cell and on his clothes. Marijuana was the only confirmed substance used by the patient while in prison.

On admission, he exhibited agitation, aggression, rambling speech, fluctuation in consciousness, and confusion. The patient expressed grandiose and paranoid delusions. He stated that he was "the president" and that the staff "was going to shoot him." He was started on benzodiazapines as well as antipsychotics to control his agitated state. During an interview on the day after admission, the patient experienced a visual hallucination. He counted six "little people" in the room. He became very paranoid and agitated as he observed and described this hallucination. The patient claimed that these "little people" engaged in humorous as well as threatening activities. He responded verbally to the activities of the images. He was unable to describe these "little men." He also claimed that he saw a redheaded man who he thought was the devil.

Physical examination of the patient revealed no abnormalities. His urine drug screen was positive for marijuana. No evidence of alcohol or any other drug use could be found in the lab work. There were no drug chromatography tests or brain imaging studies performed. Mental status examination revealed a black man of average build and height who was poorly groomed. He was oriented only to person and place. His eye contact was poor and he rapidly shifted his gaze around the room. His psychomotor activity involved aggressive shaking of his arms and hands, as if he were engaging with something or someone. His mood was agitated and he displayed a labile affect. He was able to comprehend speech, but he responded at a slow rate and he was inappropriate at times. His stream of thought exhibited tangentiality, as his attention was diverted from answering objective questions to interacting with his visual hallucinations. The patient's thought content revealed lilliputian hallucinations. $\mathrm{He}$ stated, "There are six little people in this room...people around me are being harmed ... . I see a red headed devil man." Observing the activities of the "little people" caused him to laugh at times, but he also responded to aggressive acts by yelling, "Stop hurting her!" He was unable to comment on the size of the little people or the details of their appearance. The patient denied auditory, olfactory, gustatory, and tactile components to this hallucination. The patient reported delusions of grandiosity, in which he stated that he was "getting calls from Kuwait and Iran concerning a secret meeting." He reported no suicidal or homicidal ideations. $\mathrm{He}$ refused to participate in cognitive testing. 
The patient was given a $5 \mathrm{mg}$ dose of Haldol to calm his agitation. Repeat laboratory data revealed no abnormality in his CBC or electrolytes. He continued to report these hallucinations for a few days; although, he displayed disorganized thoughts, thought broadcasting, paranoid and grandiose delusions, bizarre behavior and signs of aggression for two more weeks. He was maintained on Haldol $5 \mathrm{mg}$ tid, Cogentin $2 \mathrm{mg}$ bid, and Depakote $500 \mathrm{mg}$ bid until his manic behavior and psychotic symptoms subsided. At the time of discharge his mental status exam revealed no abnormalities and his cognitive function was fully intact. He was unable to recall his lilliputian hallucinations. He was discharged to the care of his family, maintained on his regular dose of Depakote, and was followed up by his community mental health center.

\section{DISCUSSION}

Lilliputian hallucinations are seldom reported in psychiatric literature and have not been previously recorded in a bipolar patient. Hendrickson described lilliputian hallucinations in a chronic schizophrenic patient and stated that "traditional lore in psychiatry reinforces the notion that visual hallucinations are typically of druginduced, metabolic or organic psychoses and unlikely to occur in the so-called 'functional psychoses' like schizophrenia" (15).

This patient experienced an acute manic episode; however, he also exhibited signs of psychosis. His psychosis involved primarily lilliputian hallucinations, in which he saw "little people" engaging in humorous and threatening activities. This could be described as Bipolar I disorder, manic type with psychotic features. The differential diagnoses include intoxication delirium, substance-induced psychotic disorder, substance-induced mood disorder, brief psychotic episode, and schizophreniform disorder. Several factors may have contributed to the patient's visual psychopathology.

Substance intoxication may have been the primary instigator of these hallucinations. Lilliputian hallucinations are not typically associated with marijuana use; however, they are not uncommon in hallucinogen intoxication. Takoaka described a patient who experienced lilliputian hallucinations as a result of chronic ingestion of psychoactive components of cough syrup (14). Harper attributed lilliputian hallucinations to Amantidine therapy in three of his patients (6). This patient used marijuana on a regular basis but had never experienced bizarre perceptual changes. While he was in prison he smoked some marijuana that was possibly mixed with a hallucinogen such as PCP or LSD. These hallucinogenic drugs would not have shown up on a routine urine drug screen but could leave residual effects. Drug chromatography studies would have been helpful to determine if the patient was exposed to a hallucinogen while in prison. This residual drug intoxication could have led to his state of psychotic behavior and ensuing hallucinations. If the patient was not exposed to a hallucinogen while in prison, he may have developed a marijuana-induced psychotic disorder independent of his mood disorder. Takoaka noted that, "substance-induced psychotic disorders can occur within 2 weeks of substance use" (14). 
These hallucinations and the drug use may be a result of the patient's Bipolar I disorder. At the time of the episode he was experiencing an acute manic episode. Recent noncompliance with his medication resulted in a relapse of manic behavior. According to the patient and his family, it is common for his mania to result in increased drug use and impulsivity. This patient had never experienced, prior to this episode, any psychotic symptoms. It is possible that this patient is beginning to develop psychotic symptoms as part of his Bipolar I disorder, independent of his marijuana dependence. The degree to which the patient's mood disorder contributed to this psychosis is ultimately unknown. Consequently, the patient responded well to medication and the hallucinations resolved as the mania was medically treated.

Instead of attributing this episode to a single cause it seems more likely that the culprit is a combination of the above-mentioned factors. This case provides useful insight into the treatment of the possible etiologies of lilliputian hallucinations. It appears that the psychosis in this patient is a byproduct of concurrent mania and marijuana intoxication. The successful treatment of this patient involved antipsychotics, mood-stabilizers, and benzodiazepines. Thus, it is important to carefully consider the interaction of psychotic, mood, and substance disorders in establishing the etiology and the treatment of lilliputian hallucinations.

\section{REFERENCES}

1. Asaad G, Shapiro B: Hallucinations: theoretical and clinical overview. Am J Psychiatry 1986; 143(9): 1088-1097.

2. Mason AJ: Fifty Spiritual Homilies of St. Macarius the Egyptian. New York, MacMillan, 1921, p xv.

3. Swift J: Gulliver's Travels. New York, Random House, 1950.

4. Leroy R: Les hallucinations lilliputiennes. Ann Med-psychol 1909; 10: 278-289.

5. Leroy R: The syndrome of lilliputian hallucinations. J Nerv Ment Dis 1922; 56: 325-333.

6. Harper RW, Knothe BV: Coloured lilliputian hallucinations with amantidine. Med J Aust 1973; 1: 444-445.

7. Savitsky N, Tarachow S: Lilliputian hallucinations during convalescence of scarlet fever. J Nerv Ment Dis 1941; 93: 310-311.

8. Montassut M, Sanguel H: Deux cas d'hallucinations lilliputiennes au cours de la maladie de Parchinson. Annal Med Psychol 1943; 2(1): 83.

9. Van Boggaert L: Sur les hallucinations visuelles au cours des affections organiques du cerveau contribution a l'etude du syndrome des hallucinations lilliputiennes. L'Encephale 1926; 21: 657-679.

10. Van Boggaert L: Hallucinations lilliputiennes dans un cas de tumeur cerebrale. Rev Neurol 1923; 2: 671-672.

11. Tremelloni L: Osservazioni su di un caso di allucinazioni lillipuziane nel corso di una bouffee delirante in un soggetto portatore di una oftalmopatia. Giornale di Psichiatria e di Neuropatologia 1966; 94(3): 625-636.

12. Yawger NS: Diminutive visual hallucinations in a hysterical convict. Arch Neurol Psychiatry $1925 ; 14: 64-65$.

13. Cohen MAA, Alfonso CA, Haque MM: Lilliputian Hallucinations and Medical Illness. Gen Hosp Psychiatry 1994; 16: 141-143. 
14. Takaoka K, Takata T: 'Alice in Wonderland' syndrome and Lilliputian hallucinations in a patient with substance-related disorder. Psychopathology 1999; 32(1): 47-49.

15. Hendrickson J, Adityanjee: Lilliputian hallucinations in schizophrenia: case report and review of literature. Psychopathology 1996; 29(1): 35-38.

16. Kanazawa A, Hata T: Coexistence of the Ekborn syndrome and lilliputian hallucinations. Psychopathology 1992; 25(4): 209-211.

17. Estler HC, Deckert J, et al.: Lilliputian and negative hallucinations in a patient with probable encephalomyelitis disseminata Psychopathology 1995; 28(2): 65-69. 